(SINTESE DE TEORLAS PSICOSSOCIOLÓGICAS)

Maria Aparecida F. Agniar*

Psicóloga organizacional, Diretora ilo Centro de Deserivolvimento e Planejamento Organizacional Ltda. CENDEPLANO.

\section{Fundamentos Teóricos}

A psicologia organizacional estuda o comportamento dos individuos por meio do estudo da estrutura social da organizaçāo. Ela busca a explicação para o mau funcionamento dos membros de uma organizaçāo ao nivel de sistema social e nāo ao nivel da personalidade. As organizaçōes consistem de comportamentos padronizados e o comportamento de cada individuo é determinado, em parte, pelas exigências do padrāo mais amplo.

A estrutura da organização consiste em um conjunto de acontecimentos que se repetem para completar e renovar o ciclo de atividades. A estrutura social é um conceito dinâmico. As atividades são concatenadas de modo a formar uma unidade. Um simples ciclo de acontecimentos nos dá uma forma simples de estrutura. Os ciclos também podem combinar-se formando uma estrutura maior ou um sistema de acontecimentos (Katz e Kahn). Essa rede de acontecimentos provoca reaçōes e motiva comportamentos.

Depreende-se dai a grande importância para a nsicologia organizacional do estudo da estrutura social da organizaçāo. A teoria do sistema aberto tem sido a abordagem mais eficiente para o tr'atamento dessas estruturas.

A teoria do sistema aberto, com o seu conceito de entropia, dá enfase à estreita relação existente entre a estrutura e o ambiente que o sustém; tal estrutu1'a não teria condiçōes de subsistir sem os continuos inputs que recebe do meio. Conseguientemente, a interação entre fontes energéticas de manutenção e a organização constitui uma bas? para a identificação do sistema social. O esforço humano e a motivação são as maiores fontes de manutenção de quase todas as estruturas sociais.

Segundo Katz e Kahn, uma abordagem teórica trata de relaçöes que englobam seres humanos. Quando se está preocupado com o que é específico da função de manutenção, em termos de comportamento humano, está-se, necessariamente, no nivel psicossocial. Na teoria do sistema aberto, os condutores do sistema não podem ser ignorados, porque eles fornecem o input de sustentação.

Por outro lado, outra importante caracteristica de um sistema é o processamento dos inputs de produção, que têm o objetivo de chegar a um produto final que será utilizado por algum outro grupo ou sistema. Essas funcōes de sistemas específicos podem ser identificadas pelo estudo do imput, da transformação e do resultado final, mas podem nāo ser essencialmente psicológicas como por exemplo no caso de lidal-se com os inputs de produção e exportação para o ambiente externo. 
Entretanto, no momento em que se lida com a organização de pessoas que estão encarregadas da transformação ou through-put, no sistema, estáse, novamente, no nivel psicossocial.

A teoria do sistema aberto dá ainda ao psicólogo organizacional a possibilidade de integrar macroabordagem e microabordagem da organização, ou seja, traduzir os conceitos sociológicos em um conjunto de microconceitos referentes a uma mesma área do comportamento social. Enquanto os estudos sociológicos possibilitam uma caracterização mais ampla dos fatos que estão inter-relacionados em um determinado fenômeno social, a abordagem psicológica possibilita, ao estudioso da organização, maiores detalhes sobre aquele mesmo fenômeno social.

A ỉntegração desses dois níveis leva a uma visão mais ampla e profunda da organização.

A organização como sistema aberto é constituída de subsistemas que estão em contínua interação uns com os outros e com o meio externo. Há uma acentuada dependência entre os subsistemas e uma dependência do sistema como um todo em relação ao ambiente externo. Mudanças ocorridas em um afetam os demais e, conseqüentemente, o global. O sistema receberá influências do ambiente e, por sua vez, poderá influenciá-lo, tornando-se assim um agente de mudanças.

A própria sobrevivência da organização depende do meio externo. Os inputs energéticos e os elementos de manutenção da organização são tomados do amblente e transformados em um produto; são levados para o meio externo, que os absorverá, dando origem, assim, a novas energias ou inputs para o sistema.

Os sistemas abertos têm características próprias que os diferenciam dos demais:

a) entropia negativa, ou seja, a importação de quantidade de energia maior do que a consumida nos processos de transformação e exportação;

b) o feedback ou inputs de informação, que são um tipo especial de elemento energético, que

112 têm como objetivo dar indicaçōes acerca do meio externo e do funcionamento interno do sistema;

c) a homeostase ou a tendência a atingir um estado de equilibrio interno que é alcançado mediante mudanças que o próprio sistema realiza (estas modificações podem ser provocadas quando há um mau funcionamento do sistema ou quando há mudanças no meio externo);

d) a eqüifinalidade, ou seja, a possibilidade que tem o sistema de atingir o mesmo estágio final partindo de condições iniciais diferentes e usando meios diversos.

Uma empresa é um tipo especifico de sistemà aberto, e apresenta caracteristicas de sistema so- cial. Sua estrutura é formada de acontecimentos e, consequientemente, não será independente do funcionamento da organização.

A estrutura social é um sistema planejado por pessoas e, como tal, é imperfeita. Sua duração é, de certo modo, imprevisivel: poderá ser de centenas de anos como também poderá desaparecer repentinamente. São os elementos psicológicos que fazem com que ela se mantenha como uma estrutura, ou seja, como uma rede estável de acontecimentos.

A estabilidade dos sistemas sociais deve-se a atitudes, percepçōes, crenças, motivações, hábitos e expectativas dos seres humanos.

Nos sistemas, as relações mantêm-se constantes, independentemente dos individuos envolvidos nelas. A grande variabilidade dos sistemas deve-se a diferentes objetivos de funções traçados, à variedade de comportamentos humanos e à diversidade no que tange à duração e sobrevivência da organização.

O sistema exige que seus elementos comportem-se de acordo com determinados padrões. Tais padrões garantem a eficiência organizacional. A perspectiva sistêmica postula o tratamento da eficiência pelo estudo dos padrões organizacionais de motivação.

A fim de que esses padrões produzam os resultados desejados, é necessária a utilização de um esquema analítico suficientemente compreensivo para identificar as principais fontes de variação e suficientemente detalhado para predizer as diferenças entre as várias unidades da organização. O esquema proposto por Katz e Kahn busca responder a três questões:

a) A primeira refere-se à caracterização dos comportamentos organizacionais exigidos para o efetivo funcionamento da organização. Esta caracterização deve levar em consideração o fato de que a organização exige, da maioria de seus membros, muitos padrões de comportamentos. As bases motivacionais desses comportamentos nem sempre são as mesmas.

b) A segunda diz respeito aos tipos de padrões motivacionais usados pela organização e àqueles que poderão ser usados: Nesta identificação é necessário que se considere a lógica e a psicologia de cada padrão e as diferentes conseqüências de cada um deles, para o funcionamento organizacional. Um dado padrão motivacional pode ser muito eficiente na produção de um determisado resultado comportamental, mas inteiramente ineficiente na produção de um outro.

c) A terceira e úlțima questão refere-se às condiçōes que suscitam um determinado padrão moti- 
vacional na organização. possivel identificar o tipo de motivação mais apropriado para produzir um determinado resultado comportamental, mas é necessário também que se saiba como esse motivo pode ser produzido na organização.

Os tipos de padrões de comportamentos individuais exigidos para o funcionamento e eficiência organizacional incluem:

a) pertencer e permanecer no sistema;

b) comportamento dependente, ou seja, o exercicio de um papel no sistema; e

c) comportamento inovador e espontâneo, isto é, performance além da exigida pelo papel.

Os. padrões organizacionais de motivação são definidos da seguinte forma:

\section{Padrão A - Submissão legal}

A' submissão legal garante a aceitação das prescrições do papel e do controle organizacional à base de sua legitimidade. As regras são obedecidas porque são reconhecidas como vindas de fontes legitimas de autoridade e porque podem ser forçadas mediante sanções legais.

As fontes motivacionais desse padrão são a força externa, que pode ser mobilizada para a completa obediência, e a aceitação internalizada da autoridade legitima.

Essa abordagem é limitada e incapaz de motivar as pessoas a qualquer outro comportamento além do conformismo rotineiro na execução dos papéis. Provoca problemas relativos à responsabilidade individual, decorrentes da aceitação da autoridade legitimada. $O$ indivíduo deve-se conformar às regras de seu grupo ou será punido por não fazê-lo.

Padrão B - 0 uso de recompensas ou satisfações instrumentais para introdurir os comportamentos necessários

Por esse padrão tenta-se recompensar os comportamentos desejados, esperando-se que, à medida que as recompensas aumentem, as motivações também aumentem. A característica desse padrão é a transformação da ações em instrumentos para o alcance de recompensas específicas.

As principais recompensas usadas no padrão B, são:

a) recompensas individuais, tais como incentivos em pagamentos e promoções individuais;

b) recompensas do sistema decorrentes da pertinência a ele e de antiguidade;

c) identificação instrumental com líderes organizacionais, na qual os seguidores são motivados a assegurar a aprovação dos líderes; d) associação com membros da organização para garantir a aprovação social do próprio grupo.

A atribuição de recompensas individuais é difícil, sobretudo quando há um número muito grande de pessoas, não se podendo ter critérios uniformes de atribuição; as atividades diárias são dificeis de serem notadas como excelentes; as atividades cooperativas, que impedem uma organização de se destruir, não são facilmente reconhecidas e recompensadas. Surgem dificuldades para se aplicar o padrão a contribuições que vão além das exigências dos papéis.

Para que as recompensas individuais sejam efetivas na produção de comportamentos desejados é necessário que preencham três condiçôes primárias: $1^{\circ}$ ) devem ser claramente percebidas como sendo suficientemente grandes para justificarem o esforço exigido; $2^{\circ}$ ) devem ser percebidas como diretamente relacionadas ao desempenho exigido e resultarem diretamente de sua realização; e $3^{\circ}$ ) devem ser percebidas como justas pela maior parte dos membros do sistema. Por isso são difíceis de aplicar em grande organizaçōes.

As recompensas individuais diferem das do sistema, pois essas últimas não são atribuídas com base no esforço individual e no desempenho, mas com base na pertinência ao sistema. As recompensas do sistema são mais efetivas para manter os membros dentro da organização. Podem acarretar o problema de manter pessoas com baixa motivação.

Além disso, as recompensas do sistema não levam a trabalhos de alta qualidade e grande quantidade. As pessoas não são motivadas a fazer mais do que o exigido pelos papéis.

A aprovação dos lideres organizacionais e dos companheiros de trabalho é um outro tipo de satisfação instrumental que pode trazer conseqüências positivas ou negativas para a eficiência organizacional. $O$ apoio social poderá ser fator na redução de absenteísmo, e de rotação. Somente se as normas do grupo o permitirem levará a um aumento na produção e na qualidade do trabalho.

Padrão C - Padrão internalizado de autodeterminação e de auto-expressão

As satisfações decorrem da realização e da expressão de habilidades e talentos. Auto-expressão e autodeterminação são as bases para a identificação com o trabalho, porque as satisfaçōes derivam diretamente da execução do papel.

O padrão motivacional de auto-expressão é o padrão mais eficiente para levar a um bom desempenho do papel, tanto em termos de quantidade quahto de qualidade. As gratificaçōes do in- 
divíduo decorrem da realização de seu trabalho, da expressão de suas habilidades e do exercício de suas próprias decisões.

Para que o padrão C seja eficiente, é necessário que o trabalho apresente suficiente complexidade e desafio, que as habilidades do individuo sejam adequadas e que ele tenha suficiente responsabilidade e autonomia no trabalho.

Esse padrão motivacional leva à alta produtividade, ao aumento das atividades cooperativas e à maior satisfação com o trabalho e, conseqüentemente, com a organização.

\section{Padrão D - Internalização dos valores da orga- nização}

Este padrão leva à incorporação dos objetivos e subobjetivos organizacionais, enquanto refletem valores próprios aos membros da organização e autoconceito. $\mathrm{O}$ padrão de motivação associado à expressão dos valores e à auto-identificação tem grande potencialidade para a internalização dos objetivos do sistema e, conseqüentemente, para a ativação de comportamentos não prescritos pelos papéis.

Há fatores que contribuem para a internalização dos objetivos da organização: participação em decisões importantes tomadas a respeito dos objetivos, contribuição para o desempenho da organização e participação nas recompensas.

$\mathrm{O}$ padrão $\mathrm{D}$ provoca o aumento da produtividade dos membros da organização, como também aumenta o seu comportamento espontâneo e inovador. Para que esses resultados sejam alcançados, é necessário, como ressaltam Katz e Kahn, genuina mudança em toda a estrutura da organização.

A participação apenas teórica, não concreta, dos membros da organização no processo decisório pode ocasionar disrupção e, a longo prazo, um aumento de insatisfação dos membros.

A liderança é considerada, pela abordagem sis-

114 têmica, como essencial para a eficiência da organização. $E$ definida como "qualquer ato de influência de relevância para a organização" (Katz e Kahn) : portanto, a essência do conceito de liderança está na influência que é exercida. Essa faz com que os próprios atos rotineiros sejam realizados além das exigências de rotina, como também fundamenta o exercício de forças de influência ou de controle, além das formalmente prescritas pela organização.

Pode-se encontrar, em uma organização, uma quantidade maior ou menor de controle sobre seus membros, dependendo do tipo de liderança predominante.
A influência exercida pelos atos de liderança é diferente da influência exercida pelo uso do poder legitimado, atribuído aos membros da organização pela própria organização. Alguns membros vão além do poder que lhes é atribuído e influenciam outros, pelo poder de referência (referent power) e pelo poder de especialista (expert power).

Essas fontes de influência não podem ser prescritas pela organização; dependem dos conhecimentos e da habilidade do indivíduo.

O poder de referência é a influência exercida mediante processo de identificação, isto é, o indivíduo exerce influência sobre outros porque é simpático a eles.

O poder de especialista refere-se à influência exercida pela capacidade profissional do individuo que é capaz de influenciar outros porque sua competência é reconhecida por eles.

O poder de referência e o poder de especialista, como fatores geradores de influência, são eficazes para o alcance de eficiência organizacional, pois não apresentam as características negativas da influência exercida por recompensas e punições.

A liderarçca é indispensável, pois o sistema social, sendo fruto de um planejamento, apresenta imperfeições que só poderão ser corrigidas por intermédio de comportamentos mais complexos do que aqueles previstos pelos papéis funcionais.

Como sistema aberto, a organização sofre influência constante do meio externo, sendo muitas vezes necessário introduzir mudanças organizacionais. Um estado sistêmico (ou a relação com o ambiente) que, inicialmente, era muito bom, pode-se tornar ineficiente ou completamente desajustado.

As organizações - às vezes - conseguem manter seu nivel de equilibrio interno sem fazer face à necessidade de mudanças. Em outras situações, entretanto, transformaçōes externas a obrigam a efetuar mudanças sistêmicas, estabelecendo um novo equilíbrio com o ambiente. Tal adaptação organizacional exige invenção e criatividade, muito além daquelas exigidas pelos papéis. Requer, portanto, liderança.

A dinâmica interna da organização como sistema é outra fonte de desequilibrio e conseqüente necessidade de mudanças no sistema. Por exemplo, um crescimento dinâmico exige dos membros das organizações novas funções não previstas pelos papéis.

No nivel das subestruturas organizacionais, a tendência interna é para o desequilíbrio. Nem sempre o desequilibrio observado entre os vários subsistemas pode ser corrigido por meio de uma maior integração. $\mathbf{E}$ comum a necessidade de mu- 
danças. Surge aqui novamente a necessidade da liderança.

A natureza humana dos membros dá um caráter específico à associação do individuo com a organização. Seres humanos estão associados a vários grupos ao mesmo tempo. Só parcialmente cada um está envolvido na organização em que trabalha. $O$ individuo sofre, portanto, a influência de vários fatores, e essa influência produz mudanças em seu comportamento. Tais mudanças podem ocasionar a disrupção dos padrões organizacionais de comportamento requeridos.

A disrupção desses padrões exige quase sempre adaptações e mesmo mudanças nas organizações e, conseqüentemente, exige lideranças.

As mudanças organizacionais podem também ser ocasionadas pelas modificações dos níveis motivacionais e das atitudes dos indivíduos.

Como acentuam Katz e Kahn, a liderança organizacional é sempre uma função combinada dos fatores da estrutura social e das características particulares dos indivíduos que integram a estrutura. Eles identificam na organização três categorias ou niveis de atos de liderança, que se diferenciam pelos efeitos que exercem na estrutura organizacional.

Como ato primordial na organização, é indicada a determinação da estrutura, ou seja, a mudança, a criação, a eliminação de estrutura e a formulação de políticas. Esse é o ato mais desafiador de liderança organizacional e dificilmente ocorre sem que haja fortes pressões do meio externo. Essa função de liderança é atribuída aos escalões hierárquicos mais altos da organização. Mas, para que possam exercê-la, é necessário que possuam uma perspectiva sistêmica da organização aliada à característica psicológica denominada por Katz e Kahn como carisma. Essa característica possibilita uma ligação emocional do líder com os demais membros da organização.

O preenchimento das lacunas encontradas na estrutura e a colocação de suas diferentes unidades em funcionamento constituem o segundo tipo de atos de liderança.

Referem-se ao desenvolvimento organizacional e à busca de caminhos e de meios para a implantação das políticas existentes e para o alcance dos objetivos organizacionais.

Esses atos são especialmente atribuídos aos níveis intermediários da organização. A fim de que possam exercê-los é necessário que possuam uma perspectiva interna do sistema, especialmente o know-how acerca das tarefas dos subsistemas relevantes e das suas relações com os subsistemas vizinhos.
Para que haja um desenvolvimento eficiente das estruturas suplementares é necessário que o escalão intermediário da organização seja capaz de estabelecer comunicações ascendentes e descendentes. Isto é, entender a maneira de agir dos escalões superiores, assim como as motivações e as limitações dos níveis inferiores, possibilitando, assim, o estabelecimento de comunicações entre esses níveis. Surge aqui a sua função como pinos de ligação.

A posição intermediária entre dois niveis na organização faz com que todos os indivíduos, exceto os do mais alto e os do mais baixo escalão exerçam, em um determinado momento, a função de pino de ligação, entre dois niveis da estrutura organizacional.

O terceiro e último nível de atos de liderança refere-se à administração, ou seja, ao uso da estrutura existente.

A medida que se desce na hierarquia organizacional nota-se uma significante diminuição dos atos de liderança. As atividades rotineiras de administração oferecem pouca possibilidade para o exercício da liderança, embora mesmo assim seja possivel exercê-la.

O uso da estrutura existente para produzir uma força influenciadora depende do grau do conhecimento que tem o supervisor da tarefa, da sua compreensão das regras, da sua preocupação com a justiça, com a consistência e com a eqüidade na aplicação dessas regras.

Segundo Katz e Kahn, a relativa ênfase que se dá às três formas de liderança organizacional origem, interpolação e uso da estrutura - deveria refletir a relação do sistema com o seu meio. Uma organização em um ambiente relativamente estável, com garantias de aquisição de novos inputs, necessitará dar menor atenção às mudanças do que uma organização em um ambiente que está sofrendo rápidas mudanças. Diferentes padrões de liderança serão também mais ou menos apropriados, dependendo do momento que a organização está vivendo.

Acentuam ainda, que, à medida que a organização vai-se desenvolvendo, surge entre os escalôes hierárquicos uma nítida necessidade de limitação de suas áreas de influência e uma maior ênfase na perspectiva sistêmica e no desenvolvimento de novas estruturas.

A função de liderança, em qualquer dos três niveis, deve ser distribuída e compartilhada pela maioria dos membros de uma organização.

A eficiência organizacional está relacionada ao grau de influência que os seus membros têm sobre questões de relevância para o sistema. Há muitos meios de se distribuir melhor a função de lideran- 
ça em uma organização. Pode-se distinguir: a delegação; a decisão participativa; o acesso a informações de relevância para a organização. A delegação, ou seja, a transferência de responsabilidade de um superior para um membro de nivel inferior na organização, tem provado ser um dos fatores geradores de alta produtividade.

Outro meio que os lideres formais podem usar para ampliar a função de líderança é a inclusão de seus subordinados no processo decisório relativo a questões de interesse do grupo ou da organização.

Acentua-se também a maleabilidade do supervisor para receber sugestões de seus subordinados, o que lhes possibilita influenciar nas decisões superiores.

As informações são também outro processo de distribuição na função de liderança. Essas referem-se sobretudo a recursos disponiveis, problemas, processos e demandas externas.

Uma organização participativa apresenta sistemas de comunicações adequados, possibilitando, assim, a troca de informações entre vários niveis hierárquicos e subsistemas da organização. Esse sistema de comunicações aumenta a quantidade total de influência exercida dentro de uma organização pelos seus membros, o que contribui para a sua maior eficiência.

Arnold Tannenbaum estuda o problema de maior influência ou da maior distribuição, na organização, da função de liderança, por meio do controle organizacional.

Conceitua controle como qualquer processo em que uma pessoa, ùm grupo ou uma organização de pessoas determina, isto é, afeta, intencionalmente, o comportamento de outra pessoa, grupo ou organização.

Controle, portanto, é um processo consciente de influência que um individuo, um grupo ou uma organização exerce sobre outros. Esse exercício

116 de influência gera maior poder.

Acentua Tannenbaum que a quantidade total de controle exercido na organização e a quantidade de controle exercido por cada escalão hierárquico podem variar em diferentes organizações e, na mesma organização, em diferentes situações. Não há, portanto, uma quantidade fixa de poder ou influência que pode ser exercida dentro de uma organização.

A expansão de exercício do controle ou influência sobre vários níveis hierárquicos decorre de duas condições: da expansão externa do poder no ambiente da organização e das diferentes condições internas da organização, tais como: condi- ções da estrutura que possibilitam interação e influência entre os membros; condições motivacionais que aumentam o interesse dos membros pelo exercício do controle e maior aceitação em serem controlados.

O exercicio conjunto de controle pelos vários niveis hierárquicos na organização leva à maior eficiência orgazacional.

Tannenbaum apresenta algumas distribuições hipotéticas de controle nas organizações. Sua apresentação gráfica do controle mostra três curvas distintas:

a) Curva $A$ ou autocrática: onde a maior influência é exercida pelos escalóes superiores. Os escalões da organização exercem pouca ou nenhuma influência.

b) Curva $B$ ou democrática: a maior influência é exercida pelos escalōes inferiores da organização. Os sindịcatos são exemplos típico dessa curva.

c) Curva $X$ ou poliárquica: a influência na organização é exercida conjuntamente pelos vários niveis hierárquicos, aumentando, assim, a quantidade total de controle na organização.

Essa curva é encontrada em organizaçōes participativas e altamente eficientes.

Os estilos de liderança surgem aqui como parte importante dessa fundamentação teórica. São a forma segundo a qual ocorrem na organização o processo de influência e participação.

Os estilos democrático, autocrático e laissezfaire foram substituidos por um contínuo de participação na vida da organização: os indivíduos participam em graus e maneiras diversas nas questões de relevância da organização dependendo das "situações" e dos próprios indivíduos.

$O$ modelo de líder organizacional, indicado por Katz e Kahn como o ideal, é aquele capaz de identificar objetivamente os vários atos de liderança, os membros da organização em condições de participarem dos mesmos e a extensão dessa participação. Em outros termos, quem, quando e como participa da vida da organização.

\section{REFERENCIAS BIBLIOGRAFICAS}

Tannenbaum, Arnold. Control in organization. McGraw-Hill, 1968.

Katz \& Kahn. Psicologia social das organizações. São Paulo, Atlas, 1970: 